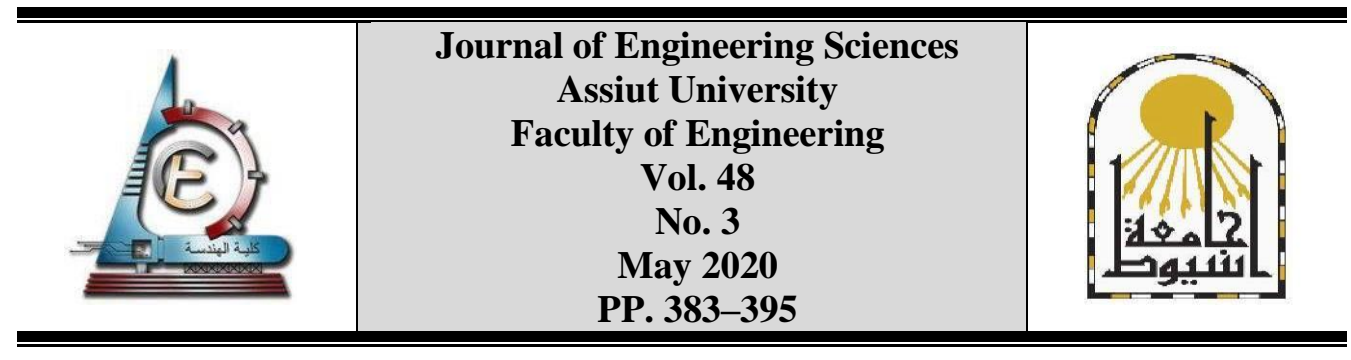

\title{
NUMERICAL INVESTIGATION OF THE EFFICIENT USE OF STIFFENERS IN COLD-FORMED CHANNELS SUBJECTED TO BENDING
}

\author{
Ayman R. Hamdallah, Ahmad Abdullah
}

Department of civil Engineering, Aswan University, Aswan 81542, Egypt.

Received 27 November 2019; Revised 31 August; Accepted 29 January 2020

\begin{abstract}
This paper presents a numerical study to identify the geometrical dimension ratios of the section that make introducing stiffeners to the cold-formed channel sections, subjected to bending, most effective. A V-shape stiffener was introduced to the web and/or the lipped flanges of such sections. A series of nonlinear finite element models has been carried out to investigate the flexural behaviour of the stiffened beam sections. The study shows that introducing stiffener to the web of channel is more effective than if it is used in the compression flange, in terms of increasing the flexural strength and delaying of local and distortional buckling failure modes. However, such effectiveness is not absolute, but it is highly dependent on the geometric properties of the section such as; flange breadth to web height ratio $\left(b_{f} / h_{w}\right)$ and web height to its thickness ratio $\left(h_{w} / t\right)$. Indeed, considering this finding would help in economic design of such sections and optimal use of material.
\end{abstract}

Keywords: Cold-formed section; Stiffeners; Finite element analyses; bending.

\section{Introduction}

Cold-formed steel (CFS) members have been widely and effectively used around the world in many applications such as roof-trusses, transmission line towers, multi-storeyed building and bridges. Most commonly CFS shapes are C-sections and Z-sections. These sections are manufactured by bending flat sheets with a thickness ranges from $0.4 \mathrm{~mm}$ to $6.4 \mathrm{~mm}$, according to Eurocode 3 (EC3) [1] and North America typical thickness ranges [2]. They have attractive advantages such as high strength to self-weight ratios, ease of installation and prefabrication and high structural efficiency.

However, CFS sections are usually characterized by excessive slenderness, which make them highly prone to buckling phenomena and unique cross-sectional deformations. These geometric failure modes do not enabling the efficient use of material. Accordingly, stiffeners and edge lips are usually common solutions to cease out-of-plane deformations of the constituting flat plates of such sections. For instance, complex edge stiffener, simple lips, perpendicular or inclined to flanges profile, have been used to improve the structural behaviour of the channel-section columns against the expected buckling failure modes [3-5]. Columns with built-up sections have been also enhanced with intermediate stiffeners $[6,7]$. 
In addition, some investigations have been conducted to study the effectiveness of introducing edge or compression flanges stiffeners [8-11], and intermediate web stiffeners [12] to CFS C and Z-sections subjected to bending. The results indicated that stiffener can improve the bending behaviour of members by delaying local and distortional buckling modes. However, the analysis of such complex stiffened section has not yet been adequately covered by design codes.

There are two analytical methods adopted in specifications to design the CFS sections [1, 13]; the direct strength method (DSM) and the effective width method (EWM). The former method is easy to apply if the studied sections are within the geometric limitations prescribed in the North American specification [13]. However, in case new section geometry is studied, the semi-empirical strength curves used to determine the ultimate strength have to be calibrated against the test results of such sections $[12,14]$. The second approach could be reliable, but very tedious, as an effective width of the stiffened element has to be calculated iteratively. The numerical approaches, however, such as finite strip method (FSM) [15] and finite element analysis (FEA) introduce a robust solution for analysing these new structural elements, in case the analytical methods are restricted to specific section dimensions and configurations.

\subsection{Significance of study}

Recent studies showed that the use of stiffeners could be an urgent need in order to get more efficient CFS sections. However, limitations to the optimum use of stiffeners, to get the ultimate benefit with less material consuming, have not been effectively studied. For these sections, experimental investigations can be the first approach to understand the structural behaviour. However, numerical approaches, due to the high resources required to perform such test campaigns, would be appropriate solution to save cost and time.

In this paper, a three-dimensional finite element model (FEM), using ABAQUS package [16], was developed to study the flexural behaviour of beams stiffened with Vshape stiffener. The model was verified against published experimental tests [12]. The effectiveness of applying different stiffening techniques to cold formed channel sections; with variety of $\left(b_{f} / h_{w}\right)$ ratios, subjected to bending is investigated. Specimens included symmetric and un-symmetric sections to get the optimum use of stiffeners. Results are presented herein in terms of the moment curvature relationships, failure modes, and ultimate load capacities. Finally, a numerical approach to determine the optimum dimension of the $\mathrm{V}$-shape stiffener is introduced and the appropriateness of using the EWM as a design approach for the CFS sections stiffened with such stiffener is verified.

\subsection{Experimental tests and initial FEA results}

Wang and Young [12] carried out experimental study on CFS stiffened channel beams at the University of Hong Kong. In their study, they tested CFS stiffened channel beams (C-1-B4) under bending loads about the major x-axis, as shown in Fig. 1. The channel sections were stiffened with both complex intermediate and edge stiffeners. They were made from high strength zinc-coated structural steel sheets of grades G500 and G550, with nominal $0.2 \%$ proof stresses of $500 \mathrm{MPa}$ and $550 \mathrm{MPa}$, respectively. The single channel section had a nominal depth of $98 \mathrm{~mm}$, a nominal flange width of $33 \mathrm{~mm}$, a nominal thickness of $1 \mathrm{~mm}$, and inside bend radius of $3.5 \mathrm{~mm}$. The edge stiffeners of the section 
profile were $13 \mathrm{~mm}$ length, while the charasterstic dimensions of the complex intermediate stiffener were $26 \mathrm{~mm}$ at 45 degrees and $18 \mathrm{~mm}$, as shown in Fig. 2.

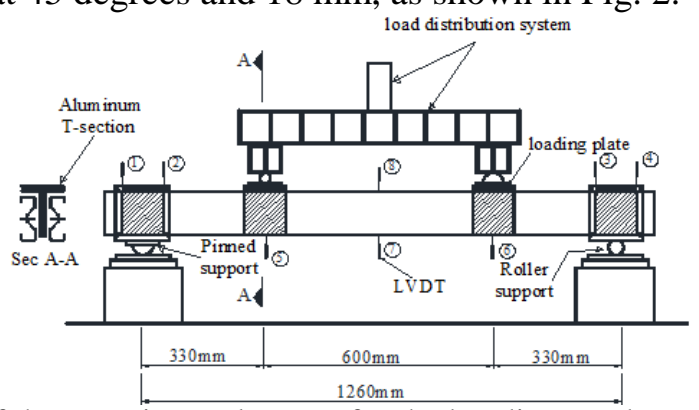

Fig. 1. Scheme of the experimental set-up for the bending test by Wang and Young [12].

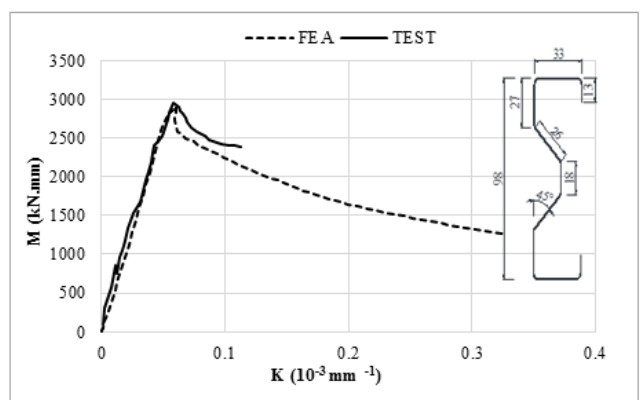

Fig. 2. Comparison of the FEA moment-curvature curve with the experimental results [12].

The test specimens were cut into a specified length of $1400 \mathrm{~mm}$ to a have a final clear test span of $1260 \mathrm{~mm}$. The reason for selecting such relatively short span was to investigate the local buckling and distortional buckling of the stiffened sections. Two identical stiffened channels (C-1-B4) were tested, under four-point bending, at the same time in order to avoid out-of-plane bending, as shown in Fig. 1. The tested beam was loaded symmetrically at two points to a T-shaped aluminium blocks through a spreader beam. Half round and round bar were also used at the terminals of the spreader beam at the two loading points. Such testing arrangement could insure pure in-plane bending of the specimens, between the two loading points, without presence of shear or axial forces. The distance between the two loading points was $600 \mathrm{~mm}$, as shown in Fig. 1. Eight LVDTs were installed at different position on the test specimens in order to measure the end support rotation (LVDTs 1-4), deflection profile and curvature (LVDTs 5-7) and the possible local or distortional buckling (LVDT 8), as shown in Fig. 1. More details of the experimental testing setup could be found in Wang and Young [12].

The beam (C-1-B4) failed within the middle third in distortional buckling interacting with a global flexural buckling failure mode. Moreover, it did not experience any out-ofplane bending during the test. The moment-curvature curve of the tested beam (C-1-B4) is shown in Fig. 2, where the recorded ultimate moment was $2985 \mathrm{kN} . \mathrm{mm}$. The beam was also analysed using the developed numerical model (ABAQUS model is denoted FEA in Fig. 2). The FEA prediction (2897 kN.mm), however, was $3 \%$ lower than the experimental moment capacity. Moreover, the model was also able to follow the post-failure behaviour 
with acceptable accuracy. So, it could be concluded that the model was able to simulate the beam behaviour reasonably in terms of ultimate load and failure mode.

\section{Finite element analysis}

The finite element package ABAQUS [16] was used to develop a nonlinear FEM of the beam subjected to two-point load shown in Fig. 1. The cross-section dimensions were used in FEM and created based on the centre line dimensions and base metal thickness.

\subsection{Material modelling}

Von-misses yield criterion along with isotropic strain hardening was used to model the material nonlinearity of the CFS. The material properties used in the FEA were that obtained from the stress-strain results of the uniaxial tensile tests given by Wang and Young [12]. The data were idealized to a bi-linear curve (linear elastic with strain hardening), in which the lower $0.2 \%$ proof stress $\left(\sigma_{0.2}\right)$, modulus of elasticity $(\mathrm{E})$ and strain at failure $\left(\varepsilon_{\mathrm{f}}\right)$ were $599 \mathrm{MPa}, 216 \mathrm{GPa}$ and 0.1 , respectively. Then, the true stress $\left(\sigma_{\text {true }}\right)$ and logarithmic plastic strain $\left(\varepsilon_{\mathrm{pl}}\right)$ were calculated to be used in the FEM. It should be mentioned that these material properties were used for both the flat portions and the fillet corners of the sections in this analysis. This because the small differences in the numerical results for including different material property might be ignored.

\subsection{Element type and mesh}

A 4-node reduced integration general shell element was used in this analysis. A sensitivity analysis was conducted among different mesh sizes of $5 \times 5 \mathrm{~mm}, 10 \times 10 \mathrm{~mm}$ and $20 \times 20 \mathrm{~mm}$. The mesh was said to be converged when an increase in the mesh density had a negligible effect on the results obtained, while the load-deformation response was the reference parameter in determining the appropriate mesh size. The convergence study showed that both the $20 \mathrm{~mm}$ and $10 \mathrm{~mm}$ mesh sizes converged to the $5 \mathrm{~mm}$ mesh size, with FEA-to-experimental load ratio $\left(\mathrm{P}_{\mathrm{FEA}} / \mathrm{P}_{\mathrm{exp}}\right)$ of $97 \%$ for beam (C-1-B4). Consequently, it was decided to adopt the $10 \mathrm{~mm}$ mesh size for the rest of the analysis, as such size was able to simulate the beam behaviour in a moderate computational time. It should be mentioned that a finer mesh at the round corners of the beam section was used.

\subsection{Loading and boundary conditions}

To simulate the two-point loading in the test set-up, a coupling constraint was used in the model, in which the load can be uniformly distributed over the small loading area through a single reference point. The load was applied at the reference points under a displacement control with a specified displacement value. This value was chosen to be greater than the measured maximum deflection in the experimental work to ensure that the FEM could simulate the full behaviour up to the ultimate load. A coupling constraint has been also used to restrain the back surface of both channel webs of beam (C-1-B4) to single point at the loading points. This would insure that the beam would not experience any out of plane deformation. The analysis was conducted with the static-Riks method. The simply supported boundary conditions were exhibited by releasing the in-plane rotation at the hinged supported (pin support) and releasing both the in-plane rotation and axial displacement along the beam at the roller support. 


\subsection{Parameters investigated and design of stiffened sections}

Channel section is the most common CFS section used in structural framing because of its easy-to use flat parts. The Sigma section, however, possesses several advantages such as high load-carrying capacity, smaller blank size, less weight, and larger torsional rigidity as compared with standard channels. Accordingly, to enhance the bending and torsional rigidity of the CFS channel sections, stiffeners could be introduced to such sections in different shapes. One, of the most common shapes is the V-shape stiffener. It could be introduced to both the web and flange of the channel section. Moreover, if it has been enlarged enough within the web it would increase both the bending capacity and torsional rigidity of the stiffened section.

Thus, the verified model was used to conduct a parametric study on the CFS stiffened lipped channel sections shown in Fig. 3. The shown sections depict the individual sectional units of the two identical sections analysed simultaneously (back to back, as shown before in Fig. 1) to avoid out of plane bending. The parameters included the $\left(b_{f} / h_{w}\right)$ ratio along with the proposed web stiffener or/and compression flange stiffener. The cross-section dimensions are summarized in Table 1 , where $h_{w}$ is the web height, $b_{f}$ is the flange width and $L_{p}$ is the perpendicular lip length. The basis of selecting these parameters is the unstiffened lipped channels mentioned in AISI standard [2]. For stiffener dimension, $\mathrm{w}_{\mathrm{h}}$ and $\mathrm{w}_{\mathrm{v}}$ are the horizontal projection and the vertical projection; respectively $\left(\mathrm{w}_{\mathrm{h}}=\mathrm{w}_{\mathrm{v}}\right.$ for inclination angle $\left.\theta=45\right)$, measured from the centre of stiffened element and were taken as a ratio of flat part equal 0 . 167. The nominal thickness of all sections is $2.5 \mathrm{~mm}$. The specimens were labelled with characteristic information such that each beam can be easily identified, as illustrated in Fig. 4 .

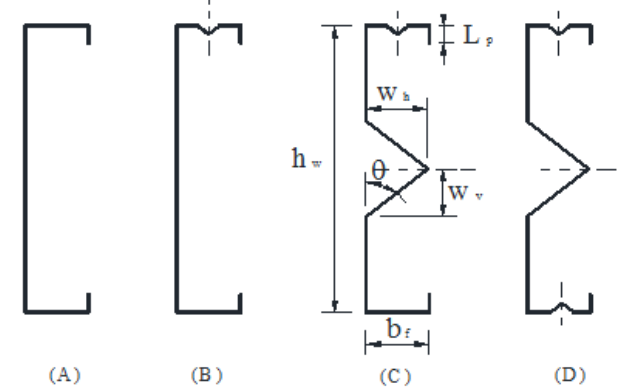

Fig. 3. Proposed lipped C-sections to FEM: a) without stiffener, b) compression flange stiffener, c) web stiffener, d) both web and flange stiffener.

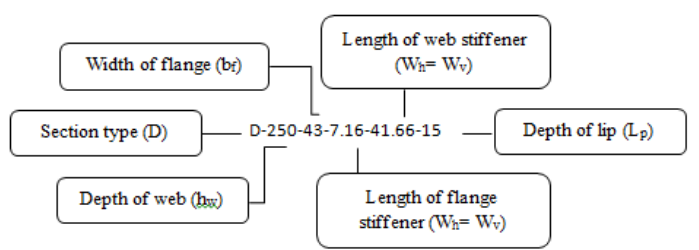

Fig. 4. Section labelling system for parametric study. 
Table 1.

Cross-section dimensions.

\begin{tabular}{|c|c|c|c|c|c|c|c|}
\hline \multirow{2}{*}{$\mathrm{b} / \mathrm{h}$} & \multirow{2}{*}{ section } & \multirow{2}{*}{$\mathrm{h}_{\mathrm{w}}$} & \multirow{2}{*}{$b_{f}$} & \multirow{2}{*}{$\mathrm{L}_{p}$} & \multicolumn{2}{|c|}{ Stiffener } & \multirow{2}{*}{ Stiffener Place } \\
\hline & & & & & $\mathrm{Wh}_{\mathrm{h}}$ & $\mathrm{W}_{\mathrm{V}}$ & \\
\hline \multirow{10}{*}{0.1} & A-375-37.5-0-0-7.5 & 375 & 37.5 & 7.5 & 0 & 0 & \\
\hline & B-375-37.5-6.26-0-7.5 & 375 & 37.5 & 7.5 & 6.26 & 6.26 & comp.fl \\
\hline & C- $375-37.5-0-62.63-7.5$ & 375 & 37.5 & 7.5 & 62.63 & 62.63 & web \\
\hline & \multirow{2}{*}{ D-375-37.5-6.26-62.63-7.5 } & \multirow{2}{*}{375} & \multirow{2}{*}{37.5} & \multirow{2}{*}{7.5} & 6.26 & 6.26 & comp.fl \\
\hline & & & & & 62.63 & 62.63 & web \\
\hline & A-430-43-0-0-15 & 430 & 43 & 15 & 0 & 0 & \\
\hline & B-430-43-7.18-0-15 & 430 & 43 & 15 & 7.18 & 7.18 & comp.fl \\
\hline & C- $-430-43-0-71.81-15$ & 430 & 43 & 15 & 71.81 & 71.81 & web \\
\hline & D-430-43-7 $18-71-81-15$ & 430 & & 15 & 7.18 & 7.18 & comp.fl \\
\hline & & 430 & 43 & 13 & 71.81 & 71.81 & web \\
\hline \multirow{5}{*}{0.2} & A- $-215-43-0-0-15$ & 215 & 43 & 15 & 0 & 0 & \\
\hline & B- $215-43-7.18-0-15$ & 215 & 43 & 15 & 7.18 & 7.18 & comp.fl \\
\hline & C- $215-43-0-35.91-15$ & 215 & 43 & 15 & 35.91 & 35.91 & web \\
\hline & \multirow{2}{*}{ D-215-43-7.18-35.91-15 } & \multirow{2}{*}{215} & \multirow{2}{*}{43} & \multirow{2}{*}{15} & 7.18 & 7.18 & comp.fl \\
\hline & & & & & 35.91 & 35.91 & web \\
\hline \multirow{9}{*}{0.3} & A-125-37.5-0-0-7.5 & 125 & 37.5 & 7.5 & 0 & 0 & \\
\hline & B- $125-37.5-6.26-0-7.5$ & 125 & 37.5 & 7.5 & 6.26 & 6.26 & comp.fl \\
\hline & C-125-37.5-0-20.87-7.5 & 125 & 37.5 & 7.5 & 20.88 & 20.88 & web \\
\hline & \multirow{2}{*}{ D- $125-37.5-6.26-20.87-7.5$} & \multirow[t]{2}{*}{125} & \multirow[t]{2}{*}{37.5} & \multirow{2}{*}{7.5} & 6.26 & 6.26 & comp.fl \\
\hline & & & & & 20.88 & 20.88 & web \\
\hline & A-143.3-43-0-0-15 & 143.3 & 43 & 15 & 0 & 0 & \\
\hline & B-143.3-43-7.18-0-15 & 143.3 & 43 & 15 & 7.18 & 7.18 & comp.fl \\
\hline & C-143.3-43-0-23.93-15 & 143.3 & 43 & 15 & 23.93 & 23.93 & web \\
\hline & D-143.3-43-7.18-23.93-15 & 143.3 & 43 & 15 & $\frac{7.18}{23.93}$ & $\frac{7.18}{23.93}$ & comp.fl \\
\hline \multirow{5}{*}{0.4} & A-107.5-43-0-0-15 & 107.5 & 43 & 15 & 0 & 0 & \\
\hline & B-107.5-43-7.18-0-15 & 107.5 & 43 & 15 & 7.18 & 7.18 & comp.fl \\
\hline & C-107.5-43-0-17.95-15 & 107.5 & 43 & 15 & 17.95 & 17.95 & web \\
\hline & \multirow{2}{*}{ D-107.5-43-7.18-17.95-15 } & \multirow[t]{2}{*}{107.5} & \multirow[t]{2}{*}{43} & \multirow[t]{2}{*}{15} & 7.18 & 7.18 & comp.fl \\
\hline & & & & & 17.95 & 17.95 & web \\
\hline
\end{tabular}

\section{Results and discussion}

As shown before in Fig. 2, the FEM provided a good correlation of the load-curvature curve all over the loading history for the CFS stiffened channel beam (C-1-B4). This ensures reliable results would be obtained for the parametric study.

In Figure (5-a) comparison among the beam sections with different stiffening techniques along with the reference beam section (A) is presented. The included sections are: section (B), where the stiffener was introduced to the compression flange; section (C), where the stiffener was introduced to the web; and section (D), where the stiffener was introduced for both the compression flange and the web. The results show that introducing stiffeners to the web and/or compression flange of CFS channels would be an effective technique in enhancing their structural behaviour by delaying buckling failure modes. However, the effectiveness of such technique is highly dependent on section geometry. For instance, introducing web stiffener of $62.3 \mathrm{~mm}$ length to a section has smaller $\left(\mathrm{b}_{\mathrm{f}} / \mathrm{h}_{\mathrm{w}}\right)$ value of 0.1 would enhance the ultimate capacity by nearly $190 \%$. However, introducing a stiffener of $6.3 \mathrm{~mm}$ length to the flange of the same section was useless in enhancing the bending strength of the sections, as shown in Fig. (5-a). On the other hand, the use of stiffeners in the web and/or flange of CFS channel having $\left(b_{f} / h_{w}\right)$ value as large as 0.3 would achieve nearly comparable enhancements in the bending capacity, as shown in Fig. (5-b). 

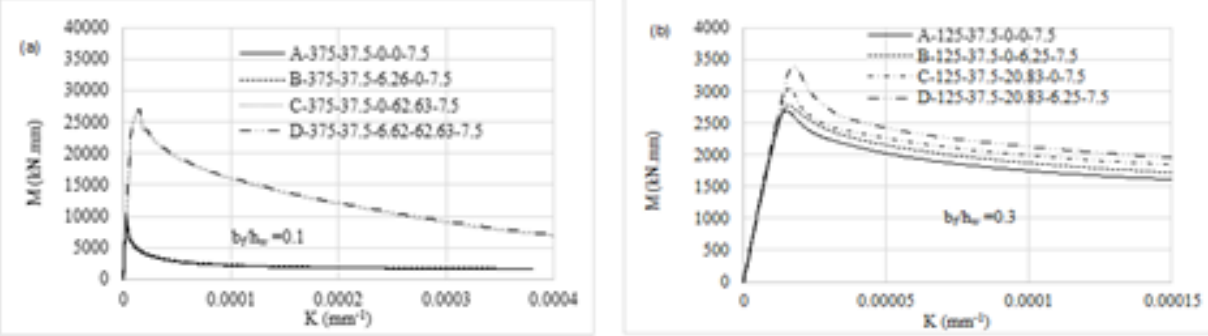

Fig. 5. Comparison of moment-curvature for beams A, B, C and D: a) $b_{f} / h_{w}=0.1$, b) $b_{f} / h_{w}=0.3$

\subsection{Effectiveness of web stiffener with variation of section geometry}

The comparison of moment-curvature curves showed that utilization of stiffener in web is an effective technique for enhancing the bending strength. The amendment of that technique mainly depends on $\left(b_{f} / h_{w}\right)$ value. When the flange breadth $\left(b_{f}\right)$ is kept constant, while the $\left(\mathrm{b}_{\mathrm{f}} / \mathrm{h}_{\mathrm{w}}\right)$ ratios are $0.1,0.2,0.3$ and 0.4 the ultimate moment increased by $151 \%$, $60.7 \%, 19.7 \%$ and $11 \%$ respectively as presented in Fig. 6. However, at a constant height of web $\left(h_{v}(b)\right.$ almost a constant enhancement would be expected in bending capacity [17]. So, the stiffener in web has a remarkable improvement in bending capacity at low $\left(b_{f} / h_{w}\right)$ ratios, but it has a negligible effect when used with higher $\left(b_{f} / h_{w}\right)$ ratios.

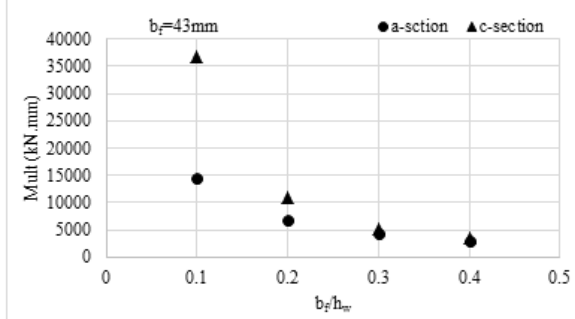

Fig. 6. FEA results of web stiffened and unstiffened channels with $b_{\mathrm{f}}=43 \mathrm{~mm}$.

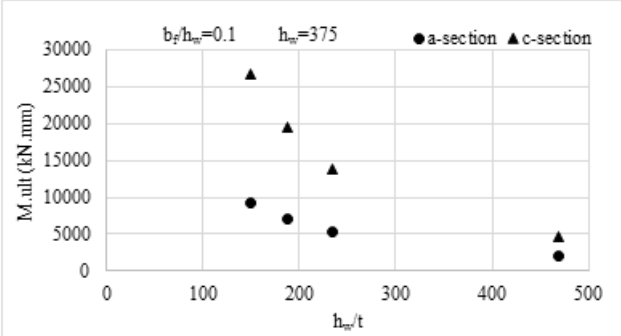

Fig. 7. FEA results of web stiffened and unstiffened channels with $h_{w}=375 \mathrm{~mm}$ and $b_{f} / h_{w}=0.1$.

Similarly, Fig. 7 shows the effect of introducing web stiffener to CFS channel with constant $\left(b_{f} / h_{w}\right)$ ratio of 0.1 and height $\left(h_{w}\right)$ of $375 \mathrm{~mm}$, while web thicknesses ranges between $0.8 \mathrm{~mm}$ to $2.5 \mathrm{~mm}$. The results indicate that the stiffener in web has a remarkable enhancement in bending capacity at low slenderness ratios $\left(\mathrm{h}_{\mathrm{w}} / \mathrm{t}\right)$, but it has a negligible effect when used in slender sections. That it is the stiffener can hardly reduce the effect of local or even distortional buckling failure modes. 


\subsection{Optimization and statistical analysis}

Structural optimization is the search for a structural design that is optimal for a certain design criterion while satisfying other constraints. In this study, Central Composite Design (CCD) was used, which is the most widely used response surface (RSM) technique [18]. CCD is a special type of RSM techniques which can deal with more than three factors with any spaced levels. For this applied mathematical analysis, Design-Expert ${ }^{\circledR}$ software [19] was used to employ the least square regression method in fitting the FE numerical data using the selected polynomial function.

As it was previously indicated, the ratios $\left(\mathrm{b}_{\mathrm{f}} / \mathrm{h}_{\mathrm{w}}\right)$ and $\left(\mathrm{h}_{\mathrm{w}} / \mathrm{t}\right)$ are considered the main influential factors in the strength enhancement ratio of CFS beams stiffened at web. Thus, the effect of five independent factors, which are $\left(b_{\mathrm{f}} / h_{w}\right)$ ratio, web height $\left(h_{w}\right)$, thickness $(t)$, the angle of inclined part measured from vertical axis $(\Theta)$ and the inclined length of the stiffener $\left(\mathrm{w}_{2}\right)$ were considered in the optimization analysis, see Fig. 8. Layers of those factors were constrained with AISI specification limitations [2] and summarized in Table 2. The first and third levels refer to the minimum and maximum value of the intended factor, respectively, while the second level refers to mean value of the factor. The ultimate moment capacity $\left(\mathrm{M}_{\mathrm{ult}}\right)$ was then determined numerically for the developed models, according the loading and boundary condition of test beam (C-1-B4) [12], in order to create the response surface model.

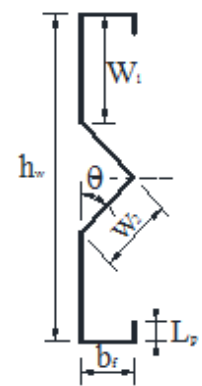

Fig. 8. Schematic diagram of stiffened CFS channel section.

It should be mentioned that a geometric restrictions have been introduced to the optimization algorithm, in order to ease the installation and manufacturing process of the section. To illustrate, the height where the stiffener would be introduced has been limited to one third of the total web height $\left(\mathrm{h}_{\mathrm{w}}\right)$. Moreover, the horizontal projection of the stiffener $\left(\mathrm{w}_{\mathrm{h}}\right)$ has been limited to the length of the flange $\left(\mathrm{b}_{\mathrm{f}}\right)$. This would set the margin of the stiffener length $\left(\mathrm{w}_{2}\right)$ to $80 \mathrm{~mm}$. Consequently, the inclination angle for the stiffener length $\left(\mathrm{w}_{2}\right)$ would range between 15 and 60 degrees, as listed in Table 2. Such geometric limitations would be expected to give enough room for fixation and installation process.

Using the factors' levels in Table 3, the optimization algorithm was defined based on $\mathrm{CCD}$ and the $108-\mathrm{M}_{\mathrm{ult}}$ obtained numerical results. For each run parameters, the FEA model was adapted to calculate the moment capacity $\left(\mathrm{M}_{\mathrm{ult}}\right)$. Probability value (P-values) for the model and significant model terms based on 5\% level of significance are presented in Table 3. The results imply that model could predict the generated values of $\mathbf{M}_{\text {ult }}$ accurately. The model also shows the residuals value $\left(\mathrm{R}^{2}\right)$ of about 0.8520 , as illustrated in Table 3 . Accordingly, the adjusted and predicted $\mathrm{R}^{2}$ values of the model were found to be in good agreement, with values of 0.8279 and 0.7827 respectively. Larger $R^{2}$ values, close to 1 with difference less than 0.2 ., imply a satisfactory regression model. 
Table 2.

Factors of optimization algorithm and their levels.

\begin{tabular}{|c|c|c|c|c|}
\hline Factors & Units & Level (1) & Level (2) & Level (3) \\
\hline $\mathrm{A}=\mathrm{b} / \mathrm{h}$ & - & 0.1 & 0.25 & 0.4 \\
\hline $\mathrm{B}=\mathrm{h}$ & $\mathrm{mm}$ & 60 & 190 & 320 \\
\hline $\mathrm{C}=\mathrm{t}$ & $\mathrm{mm}$ & 0.4 & 1.4 & 2.4 \\
\hline $\mathrm{D}=\ominus$ & degree & 15 & 37.5 & 60 \\
\hline $\mathrm{E}=\mathrm{w}_{2}$ & $\mathrm{~mm}$ & 3 & 41.5 & 80 \\
\hline
\end{tabular}

Table 3.

Pertinent model characteristics established using the RSM method.

\begin{tabular}{|c|c|c|c|c|c|}
\hline Response & $\begin{array}{c}\text { Response } \\
\text { transformation }\end{array}$ & $\begin{array}{c}\text { Adequate } \\
\text { precision }\end{array}$ & $\mathrm{R}^{2}$ & $\begin{array}{c}\text { Adjusted } \\
\mathrm{R}^{2}\end{array}$ & $\begin{array}{c}\text { Predicted } \\
\mathrm{R}^{2}\end{array}$ \\
\hline $\mathrm{M}$ ult. & $\begin{array}{c}\text { Natural Log } \\
\text { transform }\end{array}$ & 22.194 & 0.8520 & 0.8279 & 0.7827 \\
\hline
\end{tabular}

Simplification of $\mathrm{M}_{\text {ult }}$ polynomial equation was proposed in order to be used in indicating web stiffener parameters. The polynomial has been then normalized to all variables except $\left(\mathrm{w}_{2}\right)$ and $\left(\mathrm{h}_{\mathrm{w}}\right)$ at a constant angle $(\Theta)$. The maximum values of the function could be then determined for the variables $\left(\mathrm{w}_{2}\right)$ and $\left(\mathrm{h}_{\mathrm{w}}\right)$. Such point configurations could be simply represented in compatible curves, as shown in Fig. 9. The figure shows the optimum stiffeners lengths $\left(\mathrm{w}_{2}\right)$ for different web heights $\left(\mathrm{h}_{\mathrm{w}}\right)$ at a constant $\left(\mathrm{b}_{\mathrm{f}} / \mathrm{h}_{\mathrm{w}}\right)$ of 0.1 ; an angle $(\Theta)$ of 30 degrees; with most common nominal thickness (1.02, 1.8, 2.24), provided that a slenderness ratio $\left(h_{w} / t\right)$ does not exceed a value of 350 [13]. These curves could be easily used in the design process to determine the optimum configuration for the stiffened CFS channels.

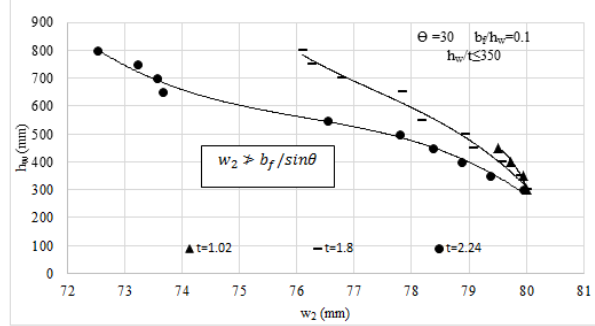

Fig. 9. Proposed design curve for stiffener with $\left(b_{\mathrm{f}} / \mathrm{h}_{\mathrm{w}}=0.1, \Theta=30\right)$.

\subsection{Effect of V-shape stiffener on elastic buckling load}

Figure 10 shows the signature curve [15] for a V-shape stiffened lipped channel compared to standard lipped channel (A) $250 \times 43 \times 15 \times 2.4 \mathrm{~mm}$ and lipped channel with intermediate web stiffener. The length of the V-shape stiffener $\left(\mathrm{W}_{2}\right)$ introduced was $50 \mathrm{~mm}$ with inclination angle $(\theta)$ of 30 degree. The results show that the $\mathrm{V}$-shape stiffener had a significant effect on enhancing both the critical elastic local and distortional buckling stresses. The increase in the critical elastic buckling load was $350 \%$ compared to the standard channel section, while that of the traditional stiffener was just $56 \%$, at applied moment load of $21819.8 \mathrm{kN} . \mathrm{mm}$. That is, the V-shape stiffening technique practically divided the web into four-small flat plates, instead of two in case of traditional web stiffener.

With respect to the distortional buckling, the enhancement in the critical distortional buckling stress was nearly $95 \%$ and $32 \%$ for the $\mathrm{V}$-shape and the traditional stiffener, 
respectively. The existence of the $\mathrm{V}$-shape stiffener within the web was able to reduce the rotation of the lipped flange at the flange/web junction in the section and hence to reduce the distortional deformations within the section. On the other hand, the V-shape stiffener was also able to shift the shear centre of the stiffened section to be much closer to the centroid of the section. Such behaviour is nearly analogous to that of the Sigma section in resisting torsional deformations. In general, the V-shape stiffener, would enhance the structural behaviour of the CFS section against; local, distortional and even torsional deformations.

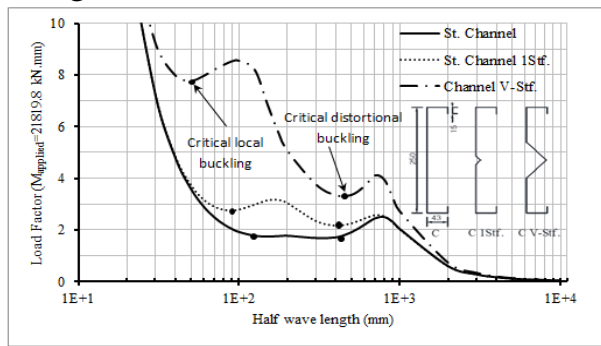

Fig. 10. Effect of V-shape stiffener on elastic buckling load.

\subsection{Comparison of FEA of optimized sections to EWM}

Since the optimized stiffened C-sections, in this study, have not been covered yet with the geometric limitations of the North American Specification [13], the DSM could not be used directly. Modified formulae depending on the section geometry have to be used in this case [12]. However, the EWM adopted in EC3 part 1-3 [1] is still applicable for such sections. A brief description for determining the the nominal flexural strength according to EC3 approach, which accounts for local and distortional buckling, is given in the following equations:

$$
M_{n}=\min \left(M_{n l} \& M_{n d}\right)
$$

Where $M_{n}$ is the nominal flexural strength, $M_{n l}$ is the nominal flexural strength due to local buckling and $M_{n d}$ is the nominal flexural due to distortional buckling.

The nominal flexural strength due to local buckling $\left(M_{n l}\right)$ is calculated based on an effective cross-section for the constituting flat parts. This reduced section resists the full bending action applied on the section. The effective widths of flat parte are calculated according to EC3 part 1-5 [20] as follow:

$$
b_{e}=b\left[\lambda_{l}-0.055(3+\psi)\right] / \lambda_{l}^{2}
$$

Where $\lambda_{l}=\sqrt{f_{y} / \sigma_{c r}}$

And $\sigma_{c r}=\frac{k \pi^{2} E t^{2}}{12\left(1-v^{2}\right) b^{2}}$

Where $b$ and $b_{e}$ are the total and the effective width of the plate, respectively, $\psi=f_{2} /$ $f_{1}$ is the minimum stress to maximum stress ratio on the plate element, $\lambda_{l}$ is the slenderness ratio for local, $f_{y}=$ yield stress which is the $0.2 \%$ proof stress buckling, $\sigma_{c r}$ is the critical elastic local buckling stress, $E$ is the Young's modulus of elasticity, $v$ is Poisson's ratio, $k$ is the buckling factor calculated according to EC3 part 1-5 [20] based on the stress ratio $\psi$ and plate boundary conditions. 
Ayman r. Hamdallah, ahmad Abdullah, Numerical investigation of the efficient use of stiffeners

For the distortional buckling, the design could be based on the assumption that the constituting plate assembly subjected to bending, within the stiffened web or flange, is longitudinally supported along its centroidal axis with spring, as shown in Fig. 11. This spring builds up its stiffness from the flexural stiffness of the adjacent plates. The EC3 part 1-3[1] states that the spring stiffness of the stiffener, $k$ is determined based on the principle of virtual work according to the following equation:

$$
K=u / \delta
$$

Where $\delta$ is the unit displacement exerted by a unit load per unit length $u$, applied at the centroid of the effective part of the cross-section, as shown in Fig. (11-a). The displacement $\delta$ is calculated according to EC3part 1-3 [1] as follow:

For an edge stiffener

$$
\delta=\emptyset b_{f}+\frac{u b_{f}^{3}}{3} * \frac{12\left(1-v^{2}\right)}{E t^{3}}
$$

And for an intermediate stiffener $\delta=\frac{2 u h_{w}^{2}}{3 h_{w}} * \frac{12\left(1-v^{2}\right)}{E t^{3}}$

The critical elastic buckling stress $\sigma_{c r, s}$ could be then calculated from:

$$
\sigma_{c r, s}=\frac{2 \sqrt{K E I_{s}}}{A_{s}}
$$

Where $K$ is the spring stiffness per unit length, $I_{s}$ is the effective second moment of area of the stiffener, taken as that of its effective area $A_{s}$ about the centroidal axis parallel to the stiffened plate element.

\begin{tabular}{|c|c|c|c|c|c|c|c|}
\hline \multirow[t]{2}{*}{ Section ${ }^{*}$} & \multirow{2}{*}{$\begin{array}{l}\text { thickness } \\
\text { (mm) }\end{array}$} & \multicolumn{2}{|c|}{ Stiffener Dim. } & \multirow{2}{*}{$\begin{array}{c}\text { FEM } \\
(\mathrm{kN} . \mathrm{mm})\end{array}$} & \multirow{2}{*}{$\begin{array}{l}\text { Failure } \\
\text { mode }\end{array}$} & \multirow{2}{*}{$\begin{array}{c}\mathrm{EC} 3 \\
(\mathrm{kN} . \mathrm{mm})\end{array}$} & \multirow{2}{*}{ FEM/EC3 } \\
\hline & & $\begin{array}{c}\mathrm{W}_{2} \\
(\mathrm{~mm})\end{array}$ & $\theta$ & & & & \\
\hline$c-190-19-0-18.3-5.7$ & 1.02 & 36.6 & 30 & 1370.6 & $\mathrm{D}+\mathrm{F}$ & 1325.3 & 1.03 \\
\hline$c-190-19-0-18.3-5.7$ & 1.8 & 36.6 & 30 & 3165.8 & $\mathrm{D}+\mathrm{F}$ & 2978.5 & 1.06 \\
\hline$c-190-19-0-19-5.7$ & 1.02 & 21.9 & 60 & 1297.7 & $\mathrm{D}+\mathrm{F}$ & 1153.7 & 1.12 \\
\hline$c-190-19-0-19-5.7$ & 1.8 & 21.9 & 60 & 3820.6 & $\mathrm{D}+\mathrm{F}$ & 3757.2 & 1.02 \\
\hline$c-190-47.5-0-18.3-14.3$ & 1.02 & 36.6 & 30 & 1832 & $\mathrm{D} \neq \mathrm{F}$ & 1876.4 & 0.98 \\
\hline$c-190-47.5-0-18.3-14.3$ & 1.8 & 36.6 & 30 & 4331.6 & $\mathrm{D}+\mathrm{F}$ & 4154.8 & 1.04 \\
\hline$c-190-47.5-0-47.5-14.3$ & 1.02 & 54.8 & 60 & 4240.5 & $\mathrm{D}+\mathrm{F}$ & 3681.6 & 1.15 \\
\hline$c-190-47.5-0-47.5-14.3$ & 1.8 & 54.8 & 60 & 10389 & $\mathrm{D}+\mathrm{F}$ & 9709.4 & 1.07 \\
\hline$c-350-35-0-33.7-10.5$ & 1.02 & 67.4 & 30 & 20691.3 & $\mathrm{~L}+\mathrm{D}+\mathrm{F}$ & 18640.8 & 1.11 \\
\hline$c-350-35-0-33.7-10.5$ & 1.8 & 67.4 & 30 & 51611.3 & $\mathrm{D}+\mathrm{F}$ & 49153.6 & 1.05 \\
\hline$c-350-35-0-35-10.5$ & 1.02 & 40.4 & 60 & 19313.4 & $\mathrm{D}+\mathrm{F}$ & 17882.7 & 1.08 \\
\hline$c-350-35-0-35-10.5$ & 1.8 & 40.4 & 60 & 66350.6 & $\mathrm{D}+\mathrm{F}$ & 60318.7 & 1.1 \\
\hline$c-350-87.5-0-33.7-26.3$ & 1.02 & 67.4 & 30 & 15222.6 & $\mathrm{~L}+\mathrm{D}+\mathrm{F}$ & 13965.7 & 1.09 \\
\hline$c-350-87.5-0-33.7-26.3$ & 1.8 & 67.4 & 30 & 38869.5 & $\mathrm{D}+\mathrm{F}$ & 37374.5 & 1.04 \\
\hline$c-350-87.5-0-87.5-26.3$ & 1.02 & 101 & 60 & 91182.9 & $\mathrm{~L}+\mathrm{D}+\mathrm{F}$ & 92103.9 & 0.99 \\
\hline$c-350-87.5-0-87.5-26.3$ & 1.8 & 101 & 60 & 218946.6 & $\mathrm{~L}+\mathrm{D}+\mathrm{F}$ & 206553.4 & 1.06 \\
\hline$c-450-45-0-40-13.5$ & 1.8 & 79.9 & 30 & 270622.1 & $\mathrm{D}+\mathrm{F}$ & 239488.6 & 1.13 \\
\hline$c-450-45-0-40-13.5$ & 2.24 & 79.9 & 30 & 476947.8 & $\mathrm{D}+\mathrm{F}$ & 429682.7 & 1.11 \\
\hline$c-450-45-0-45-13.5$ & 1.8 & 52 & 60 & 401229.0 & $\mathrm{D}+\mathrm{F}$ & 368100 & 1.09 \\
\hline$c-450-45-0-45-13.5$ & 2.24 & 52 & 60 & 849797.5 & $\mathrm{D}+\mathrm{F}$ & 786849.5 & 1.08 \\
\hline$c-450-112.5-0-40-33.8$ & 1.8 & 79.9 & 30 & 146579.6 & $\mathrm{D}+\mathrm{F}$ & 140941.9 & 1.04 \\
\hline$c-450-112.5-0-40-33.8$ & 2.24 & 79.9 & 30 & 261766.3 & $\mathrm{D}+\mathrm{F}$ & 244641.4 & 1.07 \\
\hline$c-450-112.5-0-112.5-33.8$ & 1.8 & 129.9 & 60 & 1525708.0 & $\mathrm{~L}+\mathrm{D}+\mathrm{F}$ & 1453055.2 & 1.05 \\
\hline$c-450-112.5-0-112.5-33.8$ & 2.24 & 129.9 & 60 & 2482867.6 & $\mathrm{~L} \div \mathrm{D}+\mathrm{F}$ & 2342327.9 & 1.06 \\
\hline Average & & & & & & & 1.07 \\
\hline Standard deviation & & & & & & & 0.04 \\
\hline
\end{tabular}

Table 4.

Comparison of the FEA flexural strength of the optimized sections to EC3.

* $\mathrm{W}_{\mathrm{h}}$ is used in the labelling of specimens. 
$\mathrm{L}=$ local buckling; $\mathrm{D}=$ distortional buckling; and $\mathrm{F}=$ global flexural buckling.

The flexural strength of the optimized sections determined by FEA and based on the same loading and boundary conditions previously described [12] were compared to EC3 approach (Table 4). Different geometric ranges of the optimized sections have been included in the comparison; within the geometric limits of AISI [13] and EC3 [20]. Table 4 shows that the EWM was able to predict reasonable predictions for the selected CFS sections. However, it was slightly conservative compared to the FEM predictions. The average ratio of the bending capacities predicted using FEM to the EWM determined values was 1.07 with a standard deviation of $4 \%$. So generally, the EWM could be reliable approach for predicting the bending capacity of CFS sections incorporating complex stiffeners.

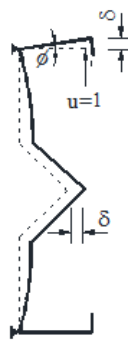

(a)

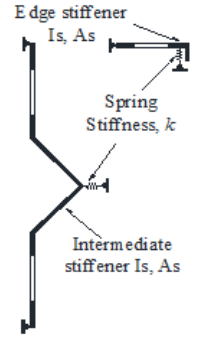

(b)

Fig. 11. Distortional buckling mode of stiffened channel section: a) distortion shape, b) analytical shape.

\section{Conclusions}

This study has investigated numerically the effectiveness of introducing stiffeners to cold-formed channel section. A nonlinear finite element model for CFS channel has been developed and verified against available test results in terms of maximum load and failure modes. A parametric study has been then conducted to identify most effective parameters in enhancing the bending capacity of stiffened CFS. Finally, an optimization methodology to identify the optimum dimensions $\left(\mathrm{W}_{2}, \theta\right)$, that make introducing stiffeners to CFS channels subjected to bending most effective, has been presented. The proposed approach outputs simplified curves which can be used in the design process of CFS channels subjected to bending. The following conclusions can be drawn:

- Applying V-shape stiffeners to web and/or compression flange would be an effective technique to delay geometric failure modes and to enhance the CFS channel behaviour in bending.

- Generally, introduced V-shape stiffeners to web of CFS channels are found to be more effective in enhancing of bending strength than those introduced to the flange of the CFS channel. That is they directly reduce the local buckling of the web, and hence indirectly the distortional buckling within the section.

- The effectiveness of web stiffeners is not absolute, but it is highly dependent on the geometric properties of the section such as; flange breadth to web height ratio $\left(\mathrm{b}_{\mathrm{f}} / \mathrm{h}_{\mathrm{w}}\right)$ and web height to its thickness ratio $\left(\mathrm{h}_{\mathrm{w}} / \mathrm{t}\right)$. Indeed, considering this conclusion would help in economic design of such sections and optimal use of material.

- The EWM is generally reliable approach and provides a reasonable prediction for the bending capacities of the CFS section stiffened with V-shape stiffener.

\section{REFERENCES}

[1] CEN. Eurocode 3: Design of steel structures, Part 1-3: General rules, supplementary rules for cold-formed members and sheeting. European Committee for Standardization, Brussels, 2005. 
Ayman r. Hamdallah, ahmad Abdullah, Numerical investigation of the efficient use of stiffeners

[2] Hancock GJ, Murray T, Ellifrit DS. Cold-formed steel structures to the AISI specification. New York: Marcel Dekker, Inc.; 2001.

[3] Zhang Y, Wang C, Zhang Z. Tests and finite element analysis of pin-ended channel columns with inclined simple edge stiffeners. Journal of Constructional Steel Research. 2007;63:383-95.

[4] Young B, Chen J. Column tests of cold-formed steel non-symmetric lipped angle sections. Journal of Constructional Steel Research. 2008;64:808-15.

[5] Young B, Yan J. Design of cold-formed steel channel columns with complex edge stiffeners by direct strength method. Journal of Structural Engineering. 2004;130:1756-63.

[6] Zhang J-H, Young B. Compression tests of cold-formed steel I-shaped open sections with edge and web stiffeners. Thin-Walled Structures. 2012;52:1-11.

[7] Young B, Chen J. Design of Cold-Formed Steel Built-Up Closed Sections with Intermediate Stiffeners. Journal of Structural Engineering. 2008;134:727-37.

[8] Wang H, Zhang Y. Experimental and numerical investigation on cold-formed steel Csection flexural members. Journal of Constructional Steel Research. 2009;65:1225-35.

[9] Haidarali MR, Nethercot DA. Local and distortional buckling of cold-formed steel beams with both edge and intermediate stiffeners in their compression flanges. Thin-Walled Structures. 2012;54:106-12.

[10] Li H, Wen Q. Study on distortional buckling performance of cold-formed thin-walled steel flexural Members with stiffeners in the flange. Thin-Walled Structures. 2015;95:161-9.

[11] JunYe, Hajirasouliha I, Becque J, Pilakoutas K. Development of more efficient coldformed steel channel sections in bending. Thin-Walled Structures. 2016;101:1-13.

[12] Wang L, Young B. Design of cold-formed steel channels with stiffened webs subjected to bending. Thin-Walled Structures. 2014;85:81-92.

[13] AISI. North American Specification for the Design of Cold-Formed Steel Structural Members. AISI S100-2016. Washington, D.C.2016.

[14] Schafer B, Sarawit A, Peköz T. Complex edge stiffeners for thin-walled members. Journal of Structural Engineering. 2006;132:212-26.

[15] Schafer BW, Ádány S. Buckling analysis of cold-formed steel members using CUFSM: conventional and constrained finite strip methods. Eighteenth international specialty conference on cold-formed steel structures2006. p. 39-54.

[16] Smith M. ABAQUS/Standard User's Manual, Version 6.14. . Simulia; 2014.

[17] Tohamy SA, Saddek AB, Abdullah A, Hamdallah AR. Numerical performance evaluation of symmetric and unsymmetric stiffeners utilization for cold-formed channels in pure bending. ICCEE2018. Hurghada: Minia University; 2018.

[18] Myers RH, Montgomery DC, Anderson-Cook CM. Response Surface Methodology: Process and Product Optimization Using Designed Experiments: John Wiley \& Sons Inc; 2009.

[19] Whitcomb PJ. Design Expert software: Version 11 Stat-Ease, Inc.; 2017.

[20] CEN. Eurocode 3: Design of steel structures, Part 1-5: Plated structural elements. European Committee for Standardization, Brussels, 2005.
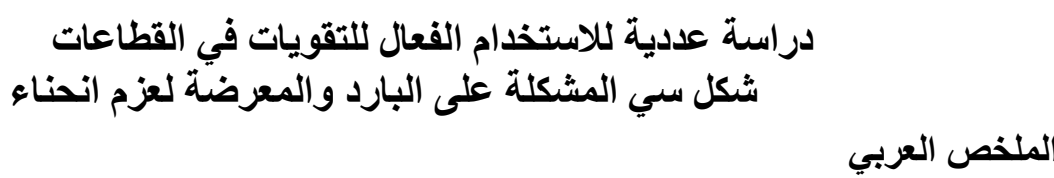

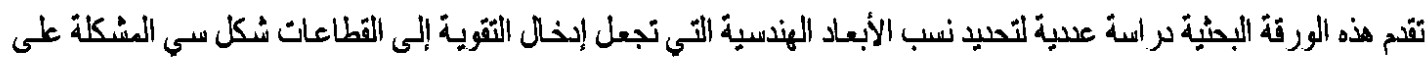

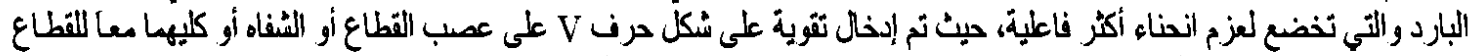

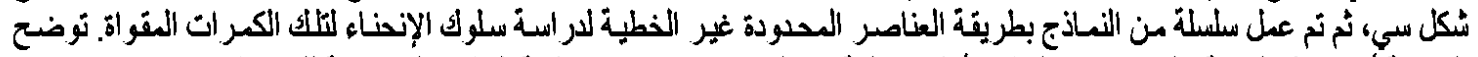

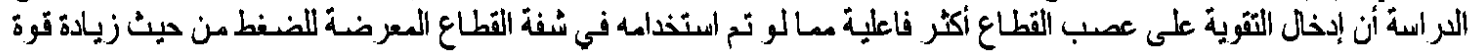

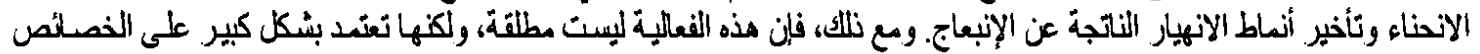

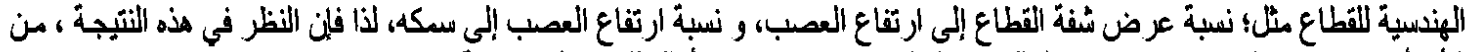

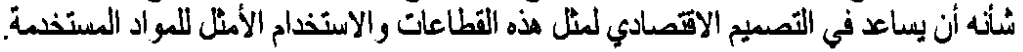

